\title{
Synthesis and Polymerization of Maleimides Containing Perfluoroalkyl Groups
}

\author{
Tsutomu Oishi,* Tetsuji Kawamoto, and Minoru Fujimoto \\ Department of Applied Chemistry and Chemical Engineering, \\ Faculty of Engineering, Yamaguchi University, \\ 2557 Tokiwadai, Ube 755, Japan
}

(Received October 19, 1993)

\begin{abstract}
Novel types of $N$-(perfluoro- $n$-octylethoxycarbonylmethyl)maleimide (PFOM) and $N$-(perfluoro- $n$-hexylethoxycarbonylmethyl)maleimide (PFHM) were synthesized from maleic anhydride, glycine and the corresponding perfluoroalkylethyl alcohols. PFOM and PFHM were polymerized with radical initiators in bulk and in several solvents at $60^{\circ} \mathrm{C}$ to $130^{\circ} \mathrm{C}$. The resulting polymers were soluble only in trifluoroacetic acid (TFAA). The highest yield and highest reduced viscosity $\left(\eta_{\mathrm{sp}} / c\right)$ for the polymers were $96 \%$ in bulk and $0.53 \mathrm{dl} \mathrm{g}^{-1}$ (in TFAA at $30^{\circ} \mathrm{C}$ ), respectively. The monomer reactivity ratios $\left(r_{1}, r_{2}\right)$ in the copolymerizations of PFOM (or PFHM) with styrene or methyl methacrylate, and Alfrey-Price $Q, e$ values for PFOM and PFHM were determined.

KEY WORDS $\quad N$-(Perfluoroalkylethoxycarbonylmethyl) maleimide/Radical Polymerization / Styrene / Methyl Methacrylate / Monomer Reactivity Ratio / $Q, e$ Values /
\end{abstract}

Several polymers containing fluorine have been synthesized and applied to many fields ${ }^{1}$ because of the characteristic properties of fluorine. $^{1,2}$ In our interest, there have been many reports ${ }^{3,4}$ on high performance liquid chromatography (HPLC) using fluorinated slica at stationary phase. This method contains some problems. ${ }^{3,4}$ Lately Hirayama reported ${ }^{5}$ that network polymers obtained from heptafluorodecyl acrylate and divinyl monomers are useful for packing of the stationary phase.

Polymerizations and copolymerizations of $N$-substituted maleimide (RMI) have widely been investigated. ${ }^{6-11}$ However, little is known concerning radical and anionic polymerizations of $\mathrm{N}$-(fluorophenyl)maleimide, ${ }^{12,13} \mathrm{~N}$ (4-(trifluoromethyl)phenyl)maleimide ${ }^{14}$ and $N$-(3-(trifluoromethyl)phenyl)maleimide. ${ }^{15}$ In addition, there have been many patents on RMI copolymers RMI bearing fluorine. ${ }^{16}$ However, there have been no reports on polymerizability and properties of the RMI-

\footnotetext{
* To whom correspondence should be addressed.
}

bearing perfluoroalkyl group. RMI polymers containing perfluoroalkyl group can be expected for the packing of HPLC because RMI polymers are very excellent in resistantsolubility for HPLC.

This paper describes the synthesis and radical and anionic polymerizations of $\mathrm{N}$-(perfluoro$n$-octylethoxycarbonylmethyl)maleimide (PFOM) and $N$-(perfluoro- $n$-hexylethoxycarbonylmethyl)maleimide (PFHM), and the copolymerizations of PFOM (or PFHM) with styrene (ST) or methyl methacrylate (MMA). Thermostabilities and physical properties of the polymers and copolymers obtained are described.

\section{EXPERIMENTAL}

\section{Synthesis of PFOM and PFHM Monomers}

PFOM and PFHM were prepared from maleic anhydride, glycine, and the corresponding perfluoroalkylethyl alcohol, as shown in 


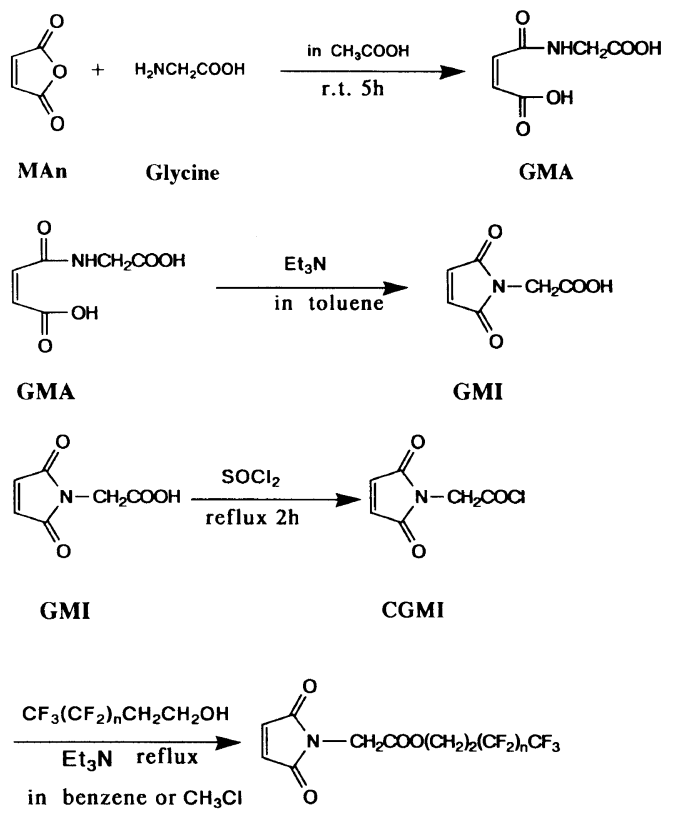

n=5 : PFHM

n=7 : PFOM

Scheme 1. PFOM and PFHM.

Scheme 1.

PFOM. $5.2 \mathrm{~g}(0.03 \mathrm{~mol})$ of $N$-[(chlorocarbonyl)methyl $]$ maleimide ${ }^{17}$ (CGMI; $82-84^{\circ} \mathrm{C}$ / $5.2 \times 10^{-3} \mathrm{mmHg}$ ) was dissolved in $40 \mathrm{ml}$ of dry chloroform. The solution was added dropwise to a mixture of perfluoro- $n$-octylethyl alcohol $(15.1 \mathrm{~g} ; 0.33 \mathrm{~mol})$ and triethylamine $(3.24 \mathrm{~g} ; 0.036 \mathrm{~mol})$ in chloroform $(80 \mathrm{ml})$ at $4-7^{\circ} \mathrm{C}$. The mixture was then stirred for $1 \mathrm{~h}$, and refluxed for $20 \mathrm{~h}$. All the reactions were accomplished under nitrogen atmosphere. The mixture was filtered to exclude triethyl ammonium salt. The filtrate was washed with water five times, and dried with anhydrous magnesium sulfate. After filtration, the filtrate was evaporated to dryness to obtain crude PFOM. It was purified by recrystallization from $n$-hexane twice: yields $41.0 \%, \mathrm{mp}$ $66.0-67.0^{\circ} \mathrm{C}$, colorless needles; IR ( $\mathrm{KBr}$ disk; $\left.\mathrm{cm}^{-1}\right): 2870\left(\mathrm{CH}\right.$ and $\left.\mathrm{CH}_{2}\right), 1750$ and 1705 $(\mathrm{O}=\mathrm{C}-\mathrm{N}-\mathrm{C}=\mathrm{O}), 1250-1100\left(\mathrm{CF}_{2}\right.$ and $\left.\mathrm{CF}_{3}\right)$, 1140 and $1185(\mathrm{C}-\mathrm{O})$, and $690($ cis $\mathrm{CH}=\mathrm{CH})$.
${ }^{1} \mathrm{H}$ NMR (chemical shift, $\delta, \mathrm{ppm}$ from tetramethylsilane (TMS) in deuterium chloroform $\left(\mathrm{CDCl}_{3}\right): 6.73(\mathrm{~s}, 2 \mathrm{H}, \mathrm{CH}=\mathrm{CH}), 4.39$ $\left(\mathrm{t}, J=6.5 \mathrm{~Hz}, 2 \mathrm{H}, \mathrm{CH}_{2} \mathrm{O}\right), 4.23(\mathrm{~s}, 2 \mathrm{H}, \mathrm{N}-$ $\mathrm{CH}_{2} \mathrm{CO}$ ), $2.50-2.32\left(\mathrm{~m}, 2 \mathrm{H}, \mathrm{CH}_{2} \mathrm{CF}_{2}\right) .{ }^{13} \mathrm{C}$ $\operatorname{NMR}\left(\delta\right.$, ppm from TMS in $\left.\mathrm{CDCl}_{3}\right): 169.58$ (CO-N-CO), 166.81 (COO), $134.50(\mathrm{CH}=$ $\mathrm{CH}), 111.21$ to $110.67\left(8 \mathrm{C}\right.$ of $\left(\mathrm{CF}_{2}\right)_{7}$ and $\mathrm{CF}_{3}$ groups), $57.59\left(\mathrm{CH}_{2}-\mathrm{O}\right), 38.47\left(\mathrm{~N}-\mathrm{CH}_{2}\right)$, and 30.46 ( $1 \mathrm{C}$ of $\mathrm{CH}_{2} \mathrm{CF}_{2}$ ).

Elemental analysis. Found: $\mathrm{C}=31.23 \%, \mathrm{H}=$ $1.40 \%, \mathrm{~N}=2.56 \%$. Calcd for $\mathrm{C}_{16} \mathrm{H}_{8} \mathrm{O}_{4} \mathrm{NF}_{17}$ : $\mathrm{C}=31.96 \%, \mathrm{H}=1.34 \%, \mathrm{~N}=2.33 \%$.

PFHM. PFHM was synthesized, according to a similar method to that of PFOM; total yield $28.4 \%$, mp. $59.0-60.0^{\circ} \mathrm{C}$. IR ( $\mathrm{KBr}$ disk; $\left.\mathrm{cm}^{-1}\right): 2870\left(\mathrm{CH}\right.$ and $\left.\mathrm{CH}_{2}\right), 1750$ and 1705 $(\mathrm{O}=\mathrm{C}-\mathrm{N}-\mathrm{C}=\mathrm{O}), 1255-1095\left(\mathrm{CF}_{2}\right.$ and $\left.\mathrm{CF}_{3}\right)$, 1140 and $1185(\mathrm{C}-\mathrm{O})$, and $690($ cis $\mathrm{CH}=\mathrm{CH})$. ${ }^{1} \mathrm{H}$ NMR $\left(\delta\right.$, ppm from TMS in $\mathrm{CDCl}_{3}: 6.73$ (s, $2 \mathrm{H}, \mathrm{CH}=\mathrm{CH}), 4.39(\mathrm{t}, J=6.5 \mathrm{~Hz}, 2 \mathrm{H}$, $\left.\mathrm{CH}_{2} \mathrm{O}\right), 4.23\left(\mathrm{~s}, 2 \mathrm{H}, \mathrm{NCH}_{2} \mathrm{CO}\right), 2.51-2.32(\mathrm{~m}$, $\left.2 \mathrm{H}, \mathrm{CH}_{2} \mathrm{CF}_{2}\right) \cdot{ }^{13} \mathrm{C} \mathrm{NMR}(\delta$, ppm from TMS in $\mathrm{CDCl}_{3}$ ): $170.04(\mathrm{CO}-\mathrm{N}-\mathrm{CO}), 167.28(\mathrm{COO})$, $134.97(\mathrm{CH}=\mathrm{CH}), 117.75$ to $110.50(6 \mathrm{C}$ of $\left(\mathrm{CF}_{2}\right)_{5}$ and $\mathrm{CF}_{3}$ groups), $58.04\left(\mathrm{CH}_{2}-\mathrm{O}\right), 38.94$ $\left(\mathrm{N}-\mathrm{CH}_{2}\right)$, and $30.91\left(1 \mathrm{C}\right.$ of $\left.\mathrm{CH}_{2} \mathrm{CF}_{2}\right)$.

Elemental analysis. Found: $\mathrm{C}=32.97 \%, \mathrm{H}=$ $1.75 \%, \mathrm{~N}=2.98 \%$. Calcd for $\mathrm{C}_{14} \mathrm{H}_{8} \mathrm{O}_{4} \mathrm{NF}_{13}$ : $\mathrm{C}=33.55 \%, \mathrm{H}=1.61 \%, \mathrm{~N}=2.80 \%$.

\section{Comonomers and Materials}

ST and MMA were purified by usual methods. ${ }^{18}$ Azobisisobutyronitrile (AIBN) was purified with recrystallization from methanol. Di- $t$-butyl peroxide (DTBP) was used without further purification. Solvents such as tetrahydrofuran (THF), dioxane (DOX), benzene (BEN), toluene (TOL), and $o$-xylene $(o-\mathrm{X})$ were purified by distillation in the presence of sodium. Chloroform (CF), chlorobenzene (CB), and methanol were purified by the usual methods. ${ }^{19}$

\section{Polymerization Procedure}

Radical bulk and solution polymerizations 
of PFOM or PFHM were carried out in a sealed glass tube with the initiator at 60 to $130^{\circ} \mathrm{C}$. After polymerization for a given time, the contents were poured into excess methanol to precipitate the polymer. The polymer was filtered, purified by reprecipitation from the trifluoroacetic acid solution to methanol, and dried under reduced pressure for 2 days.

Anionic polymerization of PFOM was performed with $n$-butyllithium ( $n$-BuLi) in THF or $\mathrm{N}, \mathrm{N}$-dimethylformamide (DMF) at $0^{\circ} \mathrm{C}$ and $-16^{\circ} \mathrm{C}$ under nitrogen atmosphere. Polymerization was terminated with a few drops of methanol using a syringe. The solution was poured into a large amount of methanol. The obtained polymer was purified by the same procedure as that of radical polymerization.

Radical copolymerizations of PFOM (or PFHM) with ST or MMA were performed with AIBN $\left(2 \times 10^{-2} \mathrm{moll}^{-1}\right)$ in toluene (TOL) at $70^{\circ} \mathrm{C}$ in a sealed tube. After a prescribed time, the contents were poured into a large amount of methanol to precipitate the copolymer. The copolymer was reprecipitated twice from the trifluoroacetic acid solution to methanol, and filtered, and dried in vacuo. The composition of the copolymer was determined from ${ }^{1} \mathrm{H}$ NMR spectra and ratios of ST/PFOM(PFHM) $=5 \mathrm{H}($ phenyl protons at 7.7 to $5.8 \mathrm{ppm}) /$ $6 \mathrm{H}\left(\mathrm{CH}-\mathrm{CH}, \mathrm{N}-\mathrm{CH}_{2}\right.$, and $\mathrm{OCH}_{2}$ at 5.0 to $3.7 \mathrm{ppm}$ ) in the ST copolymer and from the ratios of $\mathrm{MMA} /(\mathrm{PFOM}(\mathrm{PFHM})+\mathrm{MMA})=$ $3 \mathrm{H}\left(\mathrm{CH}_{3}\right.$ at 2.0 to $\left.1.0 \mathrm{ppm}\right) / 9 \mathrm{H}(-\mathrm{CH}-\mathrm{CH}-$, $\mathrm{N}-\mathrm{CH}_{2}, \mathrm{OCH}_{3}$, and $\mathrm{OCH}_{2}$ at 5.0 to $3.5 \mathrm{ppm}$ ).

\section{Measurements}

$270 \mathrm{MHz}{ }^{1} \mathrm{H}$ NMR spectra for the polymers and copolymers were obtained in deuterium trifluoroacetic acid $\left(\mathrm{CF}_{3} \mathrm{COOD}\right)$ with a JEOL EX-270. Molecular weights of the polymers and copolymers were measured by gel permeation chromatography (GPC) on a Shimadzu LC 3A equipped with a data processor, using THF as eluent and Shimadzu polystyrene gel HGS-10-15-20-40. Diagrams of TG-DSC were obtained with Rigaku Thermal
Analysis apparatus and SSC5200-DSC220 (Seiko Instrument Inc.). Reduced viscosities of the polymers were measured in trifluoroacetic acid at $30^{\circ} \mathrm{C}$. The glass transition temperature $\left(T_{\mathrm{g}}\right)$ was measured by thermal mechanical analysis (TMA) (Rigaku Thermal Analysis) and the DSC method. In TMA, a film was prepared by the casting method using trifluoroacetic acid solution. Measurement was performed at a heating rate of $10^{\circ} \mathrm{Cmin}^{-1}$ in nitrogen.

\section{RESULTS AND DISCUSSION}

\section{Homopolymerizations of PFOM and PFHM}

The results of radical bulk homopolymerizations of PFOM and PFHM are summarized in Tables I and II. In all solution polymerization systems except THF, the resulting polymer was insoluble in the solvent and precipitated. All polymers except those obtained in THF were insoluble in ordinary organic solvents and soluble only in trifluoroacetic acid. The reduced viscosity $\left(\eta_{\mathrm{sp}} / c, c=0.1 \mathrm{~g} \mathrm{dl}^{-1}\right.$ in $\mathrm{CF}_{3} \mathrm{COOH}$ at $30^{\circ} \mathrm{C}$ ) of the polymer obtained in THF was smallest $\left(\eta_{\mathrm{sp}} / c=0.03\right)$ of the polymers obtained in solvents. The reduced viscosity $\left(\eta_{\mathrm{sp}} / c=0.03\right)$ corresponded to $1.5 \times 10^{3}$ of number-average molecular weight $\left(M_{n}\right)$ and $1.8 \times 10^{3}$ of weight-average molecular weight $\left(M_{w}\right)$. Thus, the polymer was soluble in THF when $M_{n}$ of the polymers was relatively small. Consequently, only polymerization in THF proceeded homogeneously throughout. Judging from reduced viscosities shown in Tables I and II, $M_{n}$ of the polymers obtained in other solvents should be greater than that of the polymer obtained in THF. The reduced viscosity of the polymer obtained with AIBN in benzene at $70^{\circ} \mathrm{C}$ was highest and $M_{n}$ was higher than those of other polymers. This may be attributable to less chain transfer to the benzene, compared to other solvents. As shown in Figure 1, there was scarcely dependence of yield and reduced viscosity of the polymers on dielectric constants $\left(\varepsilon_{\mathrm{r}}\right)$ of solvents. 
T. Oishi, T. Kawamoto, and M. Fujimoto

Table I. Bulk and solution polymerizations of PFOM

\begin{tabular}{|c|c|c|c|c|c|c|c|c|c|}
\hline \multirow{2}{*}{ Run } & \multirow{2}{*}{$\frac{\text { PFOM }}{\mathrm{moll}^{-1}}$} & \multirow{2}{*}{$\frac{\text { Initiator }}{\times 10^{2} \mathrm{moll}^{-1}}$} & \multirow{2}{*}{$\frac{\begin{array}{c}\text { Polym. } \\
\text { solvent }^{\mathrm{a}}\end{array}}{\mathrm{ml}}$} & \multirow{2}{*}{$\frac{\begin{array}{c}\text { Polym. } \\
\text { temp }\end{array}}{{ }^{\circ} \mathrm{C}}$} & \multirow{2}{*}{$\frac{\begin{array}{c}\text { Polym. } \\
\text { time }\end{array}}{\mathrm{h}}$} & \multirow{2}{*}{$\frac{\text { Convn. }}{\%}$} & \multirow{2}{*}{$\frac{\eta_{\mathrm{sp}} / c^{\mathbf{b}}}{\mathrm{dl} \mathrm{g}^{-1}}$} & \multirow{2}{*}{$\begin{aligned} & \bar{M}_{n}^{\mathrm{c}} \\
& \times 10^{-3}\end{aligned}$} & \multirow{2}{*}{$\begin{aligned} & \bar{M}_{w}{ }^{\mathrm{c}} \\
& \times 10^{-3}\end{aligned}$} \\
\hline & & & & & & & & & \\
\hline $1-1$ & $8.32^{\mathrm{d}}$ & $\operatorname{DTBP}(7.5)^{\mathrm{e}}$ & none & 130 & 20 & 84.8 & 0.25 & & \\
\hline $1-2$ & 0.42 & DTBP (2.0) & $o-\mathrm{X} \quad(2.0)$ & 130 & 20 & 84.2 & 0.03 & & \\
\hline $1-3$ & 0.42 & DTBP (2.0) & CB $\quad(2.0)$ & 130 & 20 & 94.7 & 0.11 & & \\
\hline $1-4$ & 0.53 & AIBN (4.0) & DOX (1.6) & 70 & 20 & 33.6 & 0.03 & & \\
\hline $1-5$ & 0.52 & AIBN (4.0) & BEN (1.6) & 70 & 20 & 79.1 & 0.09 & & \\
\hline $1-6$ & 0.52 & AIBN (4.0) & THF (1.6) & 70 & 20 & 28.9 & 0.03 & & \\
\hline $1-7$ & 0.53 & AIBN (4.0) & TOL (1.6) & 70 & 20 & 88.9 & 0.07 & & \\
\hline $1-8$ & 0.42 & AIBN (2.0) & THF (2.0) & 70 & 20 & 52.7 & 0.03 & 1.5 & 1.8 \\
\hline $1-9$ & 0.42 & AIBN (2.0) & $\operatorname{DOX}(2.0)$ & 70 & 20 & 85.5 & 0.03 & & \\
\hline $1-10$ & 0.42 & AIBN $(2.0)$ & BEN (2.0) & 70 & 20 & 80.9 & 0.10 & & \\
\hline $1-11$ & 0.42 & AIBN (2.0) & TOL (2.0) & 70 & 20 & 84.2 & 0.05 & & \\
\hline $1-12$ & 0.42 & AIBN (2.0) & $\mathrm{CF} \quad(2.0)$ & 70 & 20 & 87.8 & 0.06 & & \\
\hline $1-13$ & 0.42 & AIBN $(2.0)$ & DMF (2.0) & 70 & 20 & 70.2 & 0.03 & & \\
\hline
\end{tabular}

a $o$-X, o-xylene; CB, chloro benzene; THF, tetrahydrofuran; DOX, dioxane; DMF, dimethylformamide; BEN, benzene; TOL, toluene; $\mathrm{CF}$, chloroform.

b $c=c a .1 .0 \mathrm{~g} \mathrm{dl}^{-1}$; in $\mathrm{CF}_{3} \mathrm{COOH}$.

c By GPC.

d $\times 10^{4} \mathrm{~mol}$.

e Di- $t$-butylperoxide, $\times 10^{5} \mathrm{~mol}$.

Table II. Bulk and solution polymerizations of PFHM

\begin{tabular}{|c|c|c|c|c|c|c|c|c|c|}
\hline \multirow{2}{*}{ Run } & \multirow{2}{*}{$\frac{\text { PFOM }}{\mathrm{moll}^{-1}}$} & \multirow{2}{*}{$\frac{\text { Initiator }}{\times 10^{2} \mathrm{moll}^{-1}}$} & \multirow{2}{*}{$\frac{\begin{array}{c}\text { Polym. } \\
\text { solvent }^{\mathbf{a}}\end{array}}{\mathrm{ml}}$} & \multirow{2}{*}{$\begin{array}{c}\begin{array}{c}\text { Polym. } \\
\text { temp }\end{array} \\
{ }^{\circ} \mathrm{C}\end{array}$} & \multirow{2}{*}{$\frac{\begin{array}{c}\text { Polym. } \\
\text { time }\end{array}}{\mathrm{h}}$} & \multirow{2}{*}{$\frac{\text { Convn. }}{\%}$} & \multirow{2}{*}{$\frac{\eta_{\mathrm{sp}} / c^{\mathrm{b}}}{\mathrm{dl} \mathrm{g}^{-1}}$} & \multirow{2}{*}{$\begin{array}{c}\bar{M}_{n}{ }^{\mathrm{c}} \\
\times 10^{-3}\end{array}$} & \multirow{2}{*}{$\begin{aligned} & \bar{M}_{w}^{\mathrm{c}} \\
& \times 10^{-3}\end{aligned}$} \\
\hline & & & & & & & & & \\
\hline $2-1$ & $0.99^{\mathrm{d}}$ & $\operatorname{DTBP}(3.6)^{\mathrm{e}}$ & none & 130 & 20 & 95.9 & 0.22 & & \\
\hline $2-2$ & $1.00^{\mathrm{d}}$ & $\operatorname{DTBP}(3.5)^{\mathrm{e}}$ & none & 110 & 24 & 85.2 & 0.34 & & \\
\hline $2-3$ & $1.01^{\mathrm{d}}$ & AIBN $(3.4)^{\mathrm{f}}$ & none & 70 & 48 & 63.0 & 0.53 & & \\
\hline $2-4$ & 0.50 & DTBP (2.0) & $o-\mathrm{X} \quad(2.0)$ & 130 & 20 & 81.3 & 0.04 & & \\
\hline $2-5$ & 0.51 & AIBN (5.2) & BEN (2.0) & 60 & 24 & 74.2 & 0.03 & & \\
\hline $2-6$ & 0.51 & AIBN (2.0) & THF (2.0) & 60 & 24 & 31.5 & 0.03 & 1.6 & 1.8 \\
\hline $2-7$ & 0.51 & AIBN (4.0) & DOX (2.0) & 70 & 20 & 57.7 & 0.04 & & \\
\hline $2-8$ & 0.50 & $\operatorname{AIBN}(2.0)$ & TOL (2.0) & 70 & 20 & 81.7 & 0.06 & & \\
\hline $2-9$ & 0.50 & AIBN (2.0) & CF $\quad(2.0)$ & 70 & 20 & 86.0 & 0.08 & & \\
\hline $2-10$ & 0.50 & AIBN (2.0) & THF (2.0) & 70 & 20 & 36.9 & 0.03 & & \\
\hline $2-11$ & 0.50 & AIBN (2.0) & BEN (2.0) & 70 & 20 & 75.7 & 0.11 & & \\
\hline $2-12$ & 0.50 & $\operatorname{AIBN}(2.0)$ & DOX $(2.0)$ & 70 & 20 & 81.0 & 0.04 & & \\
\hline
\end{tabular}

a $o$-X, $o$-xylene; THF, tetrahydrofuran; DOX, dioxane; DMF, dimethylformamide; BEN, benzene; TOL, toluene; $\mathrm{CF}$, chloroform.

b $c=c a .1 .0 \mathrm{~g} \mathrm{dl}^{-1}$; in $\mathrm{CF}_{3} \mathrm{COOH}$.

c By GPC.

d $\times 10^{3} \mathrm{~mol}$.

e Di- $t$-butylperoxide, $\times 10^{4} \mathrm{~mol}$.

f $\times 10^{4} \mathrm{~mol}$. 


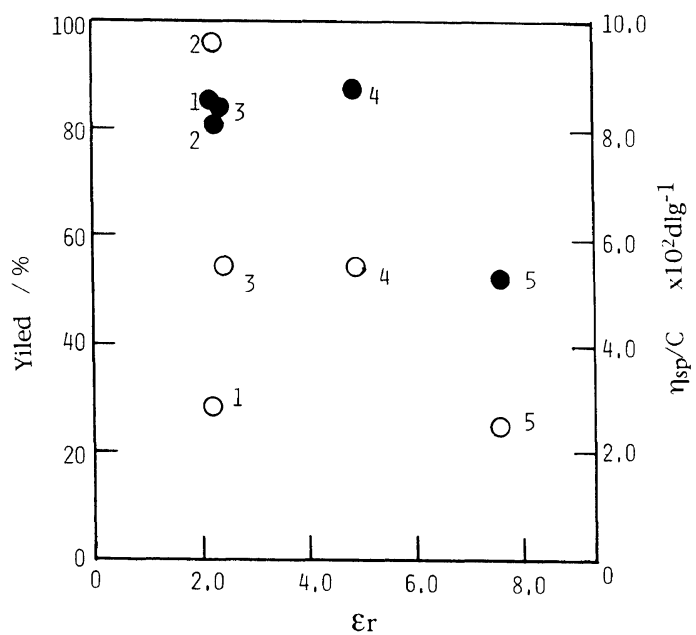

Figure 1. Relationships between yields of polymers and dielectric constants $\left(\varepsilon_{\mathrm{r}}\right)$ of solvents: (1) BEN; (2) TOL; (3) $o$-X; (4) THF; (5) DCB; (6) CHO; (O) PFOM; (O) PFHM.

Generally, yields and reduced viscosities of the polymers obtained in bulk polymerizations were much higher than those in solution polymerizations. Bulk polymerization of PFHM with AIBN gave the polymer containing the most reduced viscosity $\left(\eta_{\mathrm{sp}} / c=0.53\right.$ in Table II). The reduced viscosities of the polymers obtained in bulk at relatively high temperature $\left(110\right.$ and $\left.130^{\circ} \mathrm{C}\right)$ were $0.22-0.25$ and higher than those of the polymers obtained in solution polymerizations $\left(\eta_{\mathrm{sp}} / c=0.03-0.1^{\prime} 1\right)$.

Accordingly, it can be expected that $M_{n}$ of the polymers obtained in the bulk polymerization are greater than those of the polymers obtained in the solution polymerization because of little chain transfer to the solvent and the monomer in bulk. In addition, polymerizations in bulk homogeneously proceeded but viscosity of the solution became very high. Accordingly, the termination reaction may scarcely occur, resulting in relatively high $M_{n}$. At $130^{\circ} \mathrm{C}$, however, the resulting polymers were pale yellow and side reactions may take place. But, in ${ }^{1} \mathrm{H}$ NMR spectra of the polymers, no difference could be observed.

In the ${ }^{1} \mathrm{H}$ NMR spectra of poly(PFOM) and

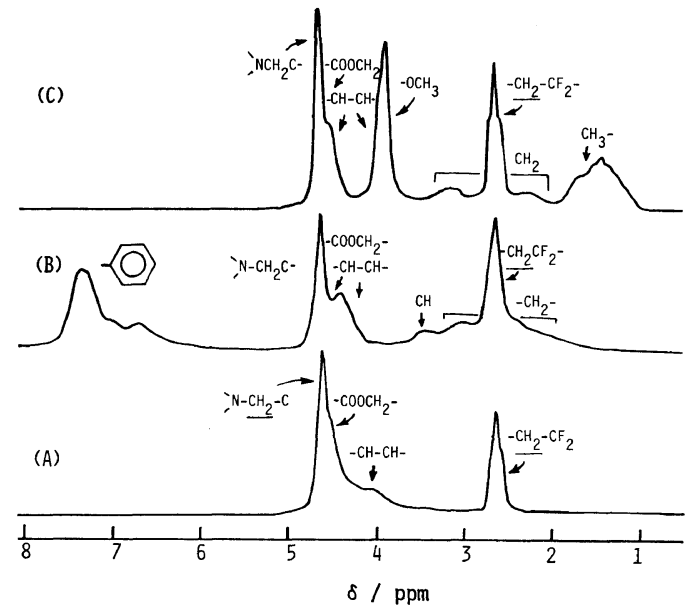

Figure 2. ${ }^{1} \mathrm{NMR}$ spectra for (A) poly(PFOM)[run 1-11], (B) poly(PFOM-co-ST) [run 4-3], and (C) poly(PFOMco-MMA) [run 4-8].

poly(PFHM), the signal assigned to a double bond of the monomer disappeared and other significant peaks could not be observed, as shown in Figure 2. ${ }^{1} \mathrm{H}$ NMR spectra for poly(PFHM) was the same as that for poly(PFOM). Thus, an ordinary addition polymerization involving double bonds may take place.

It was reported ${ }^{14,20}$ that $N$-n-hexylmaleimide (CHMI) and $N$-n-octylmaleimide (OMI) have high polymerizability and relatively high $M_{n}$. Lately it has been found that the flexibility of perfluoroethylene is similar to that of polyethylene. ${ }^{2}$ Accordingly, the perfluoroethylene group is not thought to be more rigid than ethylene group because of repulsion of fluoride itself. ${ }^{1}$ Thus, the reason for the lower polymerizabilities of PFOM and PFHM is not clear, but may be due to an ester group rather than a characteristic perfluoroalkyl group. This was recognized in isopropyl perfluoroalkyl fumarates reported previously. ${ }^{21}$

Anionic polymerizations of PFOM were performed with $n$-BuLi in THF or DMF at $0^{\circ} \mathrm{C}$ and $-16^{\circ} \mathrm{C}$. The results are summarized in Table III. In THF, yields and reduced viscosities of the polymers were relatively low. In DMF, yield and reduced viscosity were 
Table III. Anionic polymerizations of PFOM

\begin{tabular}{|c|c|c|c|c|c|c|c|}
\hline \multirow{2}{*}{ Run } & PFOM & Catalyst & $\begin{array}{l}\text { Polym. } \\
\text { solvent }^{\text {a }}\end{array}$ & $\begin{array}{c}\text { Polym. } \\
\text { temp. }\end{array}$ & $\begin{array}{c}\text { Polym. } \\
\text { time }\end{array}$ & Convn. & $\eta_{\mathrm{sp}} / c^{\mathrm{b}}$ \\
\hline & $\mathrm{moll}^{-1}$ & $\times 10^{2} \mathrm{moll}^{-1}$ & & & & $\%$ & $\mathrm{dlg}^{-1}$ \\
\hline $3-1$ & 0.42 & BuLi (3.0) & THF (2.0) & 0 & 24 & 30.6 & 0.06 \\
\hline $3-2$ & 0.42 & BuLi (6.0) & THF (2.0) & 0 & 24 & 30.8 & 0.06 \\
\hline $3-3$ & 0.42 & BuLi (3.0) & THF (2.0) & -16 & 22 & 14.8 & 0.05 \\
\hline $3-4$ & 0.42 & BuLi (6.0) & THF $(2.0)$ & -16 & 22 & 23.2 & 0.06 \\
\hline $3-5$ & 0.08 & BuLi (0.6) & DMF (10) & 0 & 24 & 84.4 & 0.24 \\
\hline $3-6$ & 0.08 & BuLi (1.2) & DMF (10) & 0 & 24 & 74.5 & 0.17 \\
\hline
\end{tabular}

a THF, tetrahydrofuran; DMF, dimethylformamide.

b $c=c a .1 .0 \mathrm{~g} \mathrm{dl}^{-1}$; in $\mathrm{CF}_{3} \mathrm{COOH}$.

Table IV. Radical copolymerization of PFOM $\left(\mathrm{M}_{1}\right)$ in toluene $(4 \mathrm{ml})$ at $70^{\circ} \mathrm{C}^{\mathrm{a}}$

\begin{tabular}{|c|c|c|c|c|c|c|}
\hline \multirow{2}{*}{ Run } & \multirow{2}{*}{$\mathrm{M}_{2}$} & \multirow{2}{*}{$\frac{\mathrm{M}_{1} \text { in monomer }}{\mathrm{mol} \%}$} & \multirow{2}{*}{$\frac{\text { Polym. time }}{\mathrm{h}}$} & \multirow{2}{*}{$\frac{\text { Convn. }}{\%}$} & \multirow{2}{*}{$\frac{\mathrm{M}_{1} \text { in copolymer }}{\mathrm{mol} \%}$} & \multirow{2}{*}{$\eta_{\mathrm{sp}} / c^{\mathrm{b}}$} \\
\hline & & & & & & \\
\hline $4-1$ & ST & 19.7 & 0.3 & 19.6 & 44.4 & 1.22 \\
\hline $4-2$ & $\mathrm{ST}$ & 38.9 & 1.0 & 18.0 & 53.9 & 0.43 \\
\hline $4-3$ & $\mathrm{ST}$ & 49.7 & 0.5 & 18.3 & 55.4 & 0.42 \\
\hline 4-4 & ST & 59.7 & 2.0 & 12.7 & 55.9 & 0.35 \\
\hline $4-5$ & ST & 79.6 & 4.0 & 10.5 & 74.6 & 0.27 \\
\hline $4-6$ & MMA & 19.9 & 2.0 & 15.7 & 10.2 & 0.22 \\
\hline $4-7$ & MMA & 39.7 & 4.0 & 9.3 & 19.9 & 0.18 \\
\hline $4-8$ & MMA & 49.1 & 18.0 & 8.7 & 25.9 & \\
\hline $4-9$ & MMA & 59.6 & 20.0 & 11.1 & 44.6 & 0.12 \\
\hline $4-10$ & MMA & 79.3 & 15.0 & 7.4 & 62.1 & 0.09 \\
\hline
\end{tabular}

${ }^{\mathrm{a}}[\mathrm{AIBN}]=2.0 \times 10^{-2} \mathrm{moll}^{-1} ; \mathrm{M}_{1}+\mathrm{M}_{2}=1.0 \mathrm{~g}$.

b $\mathrm{dlg}^{-1} ; c=c a .1 .0 \mathrm{~g} \mathrm{dl}^{-1}$; in $\mathrm{CF}_{3} \mathrm{COOH}$.

higher than those of the polymers obtained with $n$-BuLi in THF, and consistent with those of the polymers obtained with radical initiators in bulk (run 1-1 and run 2-1).

\section{Radical Copolymerizations}

Copolymerizations of PFOM $\left(\mathrm{M}_{1}\right)$ [or $\left.\operatorname{PFHM}\left(\mathrm{M}_{1}\right)\right]$ with ST $\left(\mathrm{M}_{2}\right)$ or MMA $\left(\mathrm{M}_{2}\right)$ were performed in toluene at $70^{\circ} \mathrm{C}$. The results are summarized in Tables IV and V. In all copolymerizations, some of the resulting copolymer precipitated in the solvent. The copolymers obtained were colorless and soluble only in trifluoroacetic acid, and insoluble in ordinary organic solvents. The copolymers may contain chain transfer products and side reaction products, judging from the NMR spectra in Figure 2. That is, broad peaks thought to be based on chain transfer and/or side reactions were observed around 7 and $3.2 \mathrm{ppm}$ in the poly(PFOM-co-ST) (B in Figure 2). In the poly(PFOM-co-MMA) ( $\mathrm{C}$ in Figure 2) very broad peaks due to methylene and methyl group appeared around 3.4 and $1.5 \mathrm{ppm}$, respectively.

Copolymer-composition curves are shown in Figure 3. In general, the copolymerizabilities of PFOM were similar to those of PFHM. The obtained copolymers were slightly soluble in THF when the content of PFOM (or PFHM) 
Maleimides Containing Perfluoroalkyl Group

Table V. Radical copolymerization of PFHM $\left(\mathrm{M}_{1}\right)$ in toluene $(4 \mathrm{ml})$ at $70^{\circ} \mathrm{C}^{\mathrm{a}}$

\begin{tabular}{|c|c|c|c|c|c|c|}
\hline \multirow{2}{*}{ Run } & \multirow{2}{*}{$\mathbf{M}_{2}$} & $\mathrm{M}_{1}$ in monomer & Polym. time & \multirow{2}{*}{$\frac{\text { Convn. }}{\%}$} & \multirow{2}{*}{$\frac{\mathrm{M}_{1} \text { in copolymer }}{\mathrm{mol} \%}$} & \multirow{2}{*}{$\eta_{\mathrm{sp}} / c^{\mathrm{b}}$} \\
\hline & & $\mathrm{mol} \%$ & $\mathrm{~h}$ & & & \\
\hline $5-1$ & ST & 19.6 & 0.1 & 17.7 & 46.5 & 0.62 \\
\hline $5-2$ & ST & 38.5 & 0.3 & 21.1 & 50.7 & 1.32 \\
\hline $5-3$ & ST & 49.0 & 0.3 & 12.6 & 52.4 & 0.65 \\
\hline $5-4$ & ST & 57.4 & 1.6 & 9.3 & 56.3 & 0.45 \\
\hline $5-5$ & ST & 80.1 & 1.6 & 6.7 & 70.1 & 0.31 \\
\hline $5-6$ & MMA & 19.9 & 3.0 & 12.4 & 12.3 & 0.29 \\
\hline $5-7$ & MMA & 39.5 & 9.0 & 12.1 & 25.2 & 0.30 \\
\hline $5-8$ & MMA & 48.4 & 7.0 & 13.2 & 32.6 & 0.27 \\
\hline $5-9$ & MMA & 54.3 & 4.0 & 12.2 & 37.8 & 0.20 \\
\hline $5-10$ & MMA & 79.8 & 3.0 & 13.4 & 67.0 & 0.11 \\
\hline
\end{tabular}

${ }^{\mathrm{a}}[\mathrm{AIBN}]=2.0 \times 10^{-2} \mathrm{mol1}^{-1} ; \mathrm{M}_{1}+\mathrm{M}_{2}=1.0 \mathrm{~g}$.

${ }^{b} \mathrm{dl} \mathrm{g}^{-1} ; c=c a .1 .0 \mathrm{~g} \mathrm{dl}^{-1}$; in $\mathrm{CF}_{3} \mathrm{COOH}$.

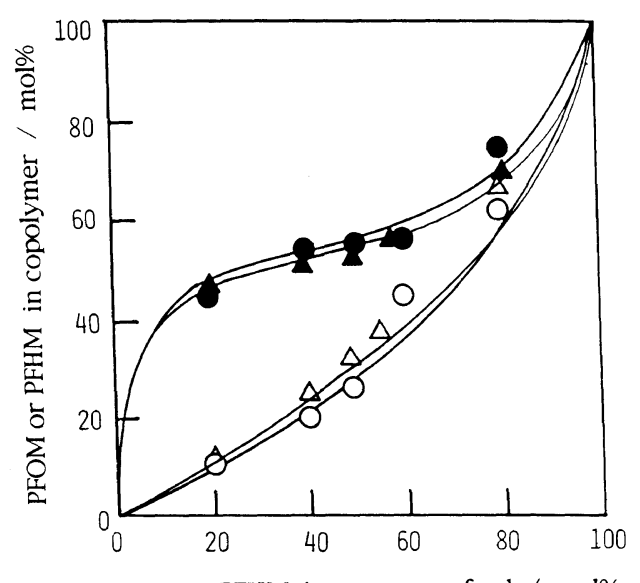

PFOM or PFHM in monomer feed / mol\%

Figure 3. Copolymer-composition curves for (O) PFOM-

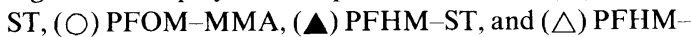
MMA systems.

in the copolymer was less than $30 \mathrm{~mol} \%$. The amount was less than $4 \mathrm{wt} \%$ of the copolymer.

The monomer reactivity ratios $\left(r_{1}, r_{2}\right)$ were calculated from the High-Conversion method reported by Tüdös and co-workers. ${ }^{22}$ From $r_{1}$ and $r_{2}$ values, Alfrey-Price ${ }^{23} Q$ and $e$ were determined. These copolymerization parameters are shown in Table VI. Differences of the parameters between PFOM and PFHM could not be detected. However, $Q$ and $e$ determined from ST systems were different
Table VI. Copolymerization parameters in toluene at $70^{\circ} \mathrm{C}$

\begin{tabular}{cccccc}
\hline $\mathrm{M}_{1}$ & $\mathrm{M}_{2}$ & $r_{1}$ & $r_{2}$ & $Q_{1}$ & $e_{1}$ \\
\hline PFOM & MMA & 0.40 & 2.29 & 0.37 & 0.69 \\
PFOM & ST & 0.39 & 0.05 & 3.80 & 1.16 \\
PFHM & MMA & 0.28 & 1.87 & 0.55 & 1.20 \\
PFHM & ST & 0.29 & 0.07 & 3.11 & 1.20 \\
\hline
\end{tabular}

from those determined from MMA systems. This was remarkably evident in ST systems reported so far. ${ }^{24,25}$ That is, $Q$ for RMI calculated from the copolymerization of RMI with ST are abnormal because of the formation of a charge transfer (CT) complex. Alfrey-Price $Q$ and $e$ theory ${ }^{23}$ does not consider steric hindrance of monomer. It is not considered that RMI can completely ignore steric hindrance because of 1,2-disubstituted ethylene and cyclic alkene structure of RMI. This may give different $Q$ and $e$ between ST and MMA systems. Compared with $Q$ and $e$ reported previously, ${ }^{26,27} Q$ and $e$ for PFOM and PFHM indicate PFOM and PFHM to be electronaccepting conjugative monomers.

$\mathrm{X}$-Ray diffraction diagrams (XRD) for the poly(PFOM) [run 1-11], poly(PFOM-co-ST) [run 4-3], and poly(PFOM-co-MMA) [run 4-8], and PFOM monomer are shown in Figure 
4. XRD for poly(PFHM) was similar to that of poly(PFOM). One broad peak was observed at about $2 \theta=$ about $17 \mathrm{deg}$. Both polymers were

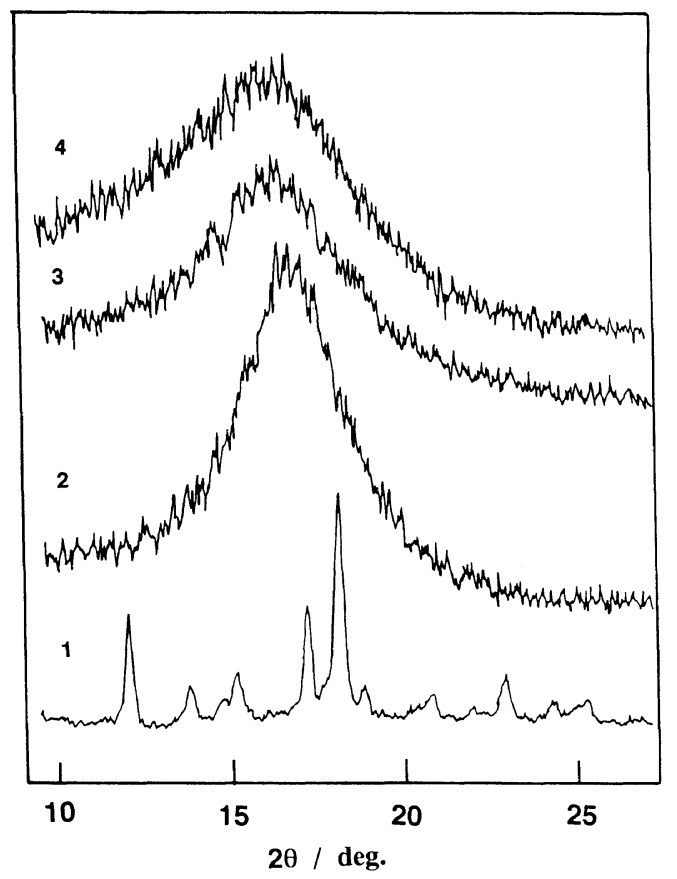

Figure 4. X-Ray diffraction diagrams (XRD) for (1) PFOM monomer, (2) poly(PFOM) [run 1-11], (3) poly(PFOM-co-ST) [run 4-3], and (4) poly(PFOM-co-MMA) [run 4-8]. found to be almost amorphous. This was also recognized in fumarates containing perfluoroalkylethyl groups reported previously. ${ }^{21}$

Diagrams of a thermogravimetric (TG) and a differential scanning calorimetric (DSC) analysis for the poly(PFOM), poly(PFOM-co$\mathrm{ST}$ ) and poly(PFOM-co-MMA) are shown in Figure 5. TG-DSC curves for the PFHM polymers and copolymers indicated similar patterns to those for PFOM polymers and copolymers. In all TG-DSC curves, three endothermal peaks were observed due to (A) a glass transition temperature $\left(T_{\mathrm{g}}\right),(\mathrm{B})$ a softening point $\left(T_{\mathrm{m}}\right)$, and (C) a degradation temperature $\left(T_{\mathrm{d}}\right)$ of the polymer and copolymers. The initial degradation temperature $\left(T_{\mathrm{d}}\right)$, which means the beginning of weight loss of the polymer, was observed at about $320^{\circ} \mathrm{C}$.

Glass transition temperatures $\left(T_{\mathrm{g}}\right)$ of the polymers were measured by thermal mechanical analysis (TMA) and DSC. Relationships between $T_{\mathrm{g}} \mathrm{s}$ and compositions of the copolymers are shown in Figure 6. In ST and MMA systems, in general, $T_{\mathrm{g}} \mathrm{s}$ determined with DSC method ( $\square$, MMA systems; $\square$, ST systems in Figure 6) were higher than those by TMA ( $\bigcirc$, MMA systems; , ST systems in Figure 6). In

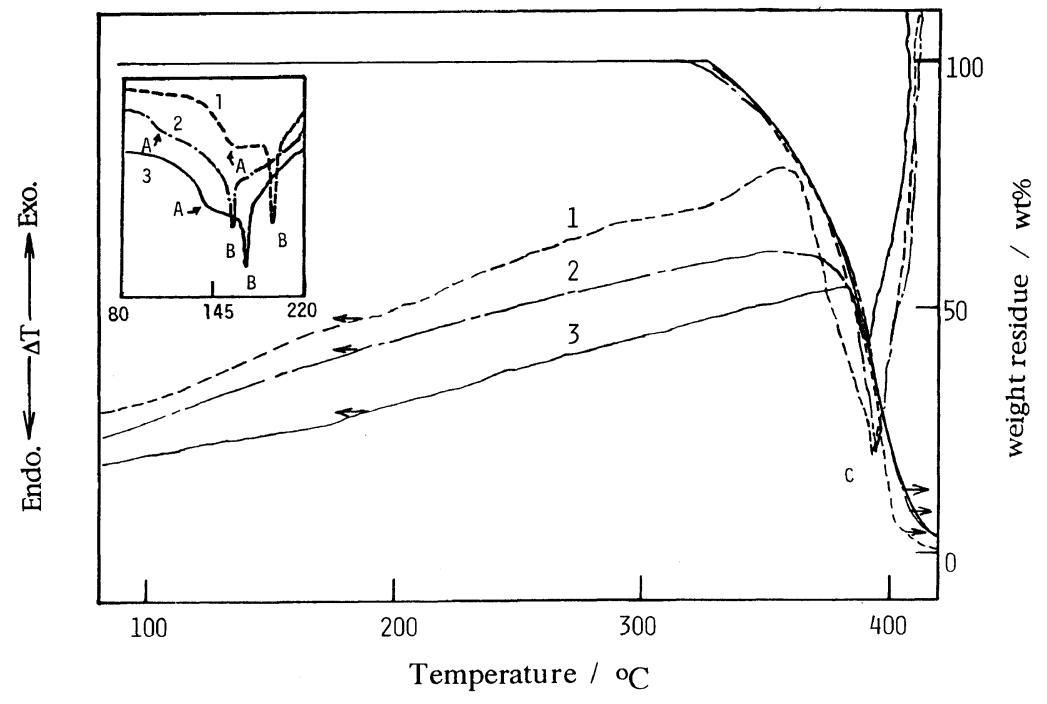

Figure 5. TG-DSC curves for (1) poly(PFOM) [run 1-11], (2) poly(PFOM-co-ST) [run 4-3], and (3) poly(PFOM-co-MMA) [run 4-8] at a heating rate of $10^{\circ} \mathrm{C} \mathrm{min}^{-1}$ in helium. 


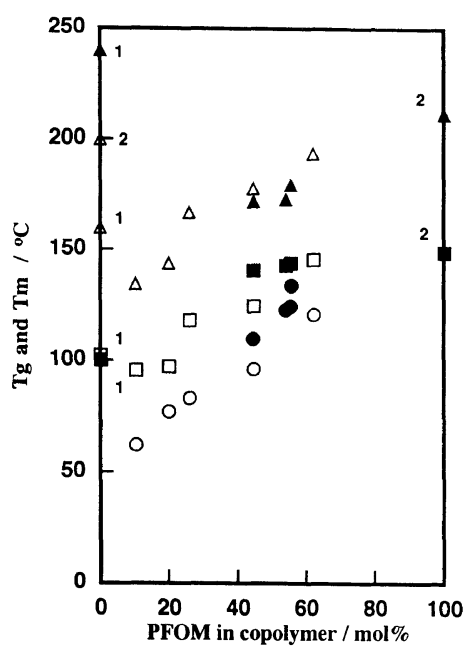

Figure 6. Dependence of glass transition temperatures $\left(T_{\mathrm{g}}\right)$ and softening points $\left(T_{\mathrm{m}}\right)$ on compositions of copolymers: $T_{\mathrm{g}}$ determined with TMA method: (O) poly(PFOM-co-ST) and (O) poly(PFOM-co-MMA); $T_{\mathrm{g}}$ determined with DSC method: ( $)$ poly(PFOM-co-ST), ( $\square$ ) poly(PFOM-co-MMA), ( $\square$ 1) poly(MMA), ( $\square$ 1) poly(ST), and ( $\left.\mathbf{Q}^{2}\right)$ poly(PFOM); $T_{\mathrm{m}}$ determined with DSC: $(\triangle)$ poly(PFOM-co-MMA), $(\triangle)$ poly(PFOM-co-ST), $(\triangle 1)$ isotactic poly(MMA), $(\triangle 2)$ syndiotactic poly(MMA), $(\boldsymbol{\Delta} 1) \operatorname{poly}(\mathrm{ST})$ [see ref 26], and ( $\mathbf{\Delta} 2)$ poly(PFOM).

PFOM systems, $T_{\mathrm{g}} \mathrm{s}$ of the copolymers were lower than those of poly(ST) $\left(T_{\mathrm{g}}=100^{\circ} \mathrm{C}\right)^{26}$ and poly(MMA) $\left(T_{\mathrm{g}}=105^{\circ} \mathrm{C}\right) .{ }^{26}$ When the content of PFOM was less than $20 \mathrm{~mol} \%$ in the copolymers. The reason for this is not clear, $T_{\mathrm{g}} \mathrm{s}$ slightly increased with the content of PFOM in the copolymers. $T_{\mathrm{m}} \mathrm{s}$ of copolymers was also lower than that of poly(ST) $\left(T_{\mathrm{m}}=240^{\circ} \mathrm{C}\right)^{26}$ or poly(MMA) $\left(T_{\mathrm{m}}=160\right.$ and $\left.200^{\circ} \mathrm{C}\right),{ }^{26}$ which was not anticipated. The reason for this is not clear, but may be due to side reactions, as can be seen from Figure 2 (B and C). That is, broad peaks thought to be based on chain transfer and/or side reactions were observed around 7 and $3.2 \mathrm{ppm}$ in the poly(PFOM-co-ST) and around $3.4 \mathrm{ppm}$ in the poly(PFOM-co-MMA), as described above.

The reduced viscosities $\left(\eta_{\mathrm{sp}} / c\right)$ of poly(PFOM-co-ST)s containing $50 \mathrm{~mol} \%$ of PFOM were highest, as shown in Figure 7, and decreased with increase of PFOM content in

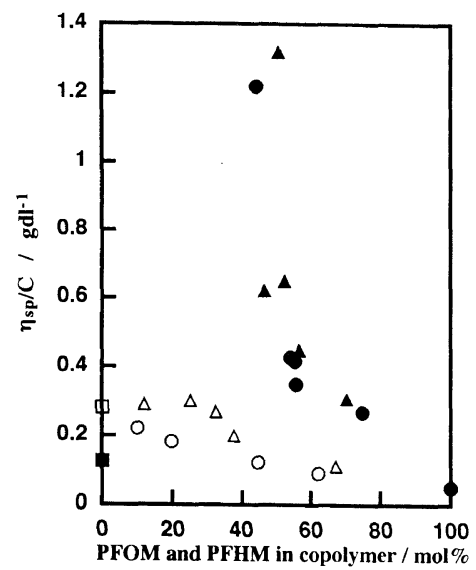

Figure 7. Relationship between reduced viscosities $\left(\eta_{\mathrm{sp}} / c\right)$ and composition of copolymers: (O) poly(PFOM-co-ST); (O) poly(PFOM-co-MMA); ( $\mathbf{A})$ poly(PFHM-co-ST); $(\triangle)$ poly(PFHM-co-MMA); ( $\mathbf{\square})$ poly(ST); ( $\square$ ) poly(MMA) [see ref 26].

the copolymers. This was also observed in poly(PFHM-co-ST)s. These results can be understood from the fact alternating copolymerization character was high in the PFOM (or PFHM)/ST systems, and copolymerization rate was large, and $M_{n}$ of the copolymers obtained should be high. In general, reduced viscosities for the poly(PFOM-co-MMA)s were lower than those for poly(PFOM-co-ST)s, and decreased with increase of PFOM content in the copolymers. The reduced viscosity $\left(\eta_{\mathrm{sp}} /\right.$ $c=0.03)$ for the homopolymer corresponded to $1.5 \times 10^{3}$ of $M_{n}$ and $1.8 \times 10^{3}$ of $M_{w}$, as described above. Accordingly, $M_{n}$ and $M_{w}$ of the copolymers should thus be much higher than those for the homopolymers.

\section{CONCLUSIONS}

1) Novel $N$-(perfluoro- $n$-octylethoxycarbonylmethyl)maleimide (PFOM) and $N$-(perfluoro- $n$-hexylethoxycarbonylmethyl)maleimide (PFHM) were synthesized from maleic anhydride, glycine and corresponding perfluoroalkylethyl alcohols.

2) PFOM and PFHM were polymerized radically and anionically to obtain the 
polymers in relatively high yields.

3) All polymers were insoluble in ordinary organic solvents, and soluble in only trifluoroacetic acid.

4) From the results of radical copolymerizations, monomer reactivity ratios and $Q-e$ were determined as follows: $r_{1}=0.39, r_{2}=0.050$, $Q_{1}=3.80, e_{1}=1.16$ in the PFOM $\left(\mathrm{M}_{1}\right)-\mathrm{ST}$ $\left(\mathrm{M}_{2}\right) ; r_{1}=0.40, r_{2}=2.29, Q_{1}=0.37, e_{1}=0.69$ in the PFOM $\left(\mathrm{M}_{1}\right)$-MMA $\left(\mathrm{M}_{2}\right) ; r_{1}=0.29$, $r_{2}=0.070, Q_{1}=3.11, e_{1}=1.20$ in the PFHM $\left(\mathrm{M}_{1}\right)$-ST $\left(\mathrm{M}_{2}\right) ; r_{1}=0.28, r_{2}=1.87, Q_{1}=0.55$, $e_{1}=1.20$ in the PFHM $\left(\mathrm{M}_{1}\right)$-MMA $\left(\mathrm{M}_{2}\right)$.

5) The highest reduced viscosities $\left(\eta_{\mathrm{sp}} / c\right)$ for poly(PFOM) and poly(PFHM) were 0.24 and $0.53 \mathrm{dlg}^{-1}\left(30^{\circ} \mathrm{C}\right.$ in trifluoroacetic acid), respectively. The highest reduced viscosity for the copolymers was about $1.3 \mathrm{dlg}^{-1}$.

Acknowledgments. We are indebted to $\mathrm{Mr}$. M. Momoi for carrying out the elemental analysis and Dr. K. Katoh in Nippon Oil \& Fats Co., Ltd. for supplying the perfluoroalkyl alcohols.

\section{REFERENCES}

1. K. Ihara and S. Koujiya, "Fussokei Polymer," Kyoritsu Shuppan, Tokyo, 1990; L. A. Wall, Ed., "Fluoropolymers," Wiley-Interscience, New York, N.Y., 1972; R. E. Banks, Ed., "Preparation, Properties and Industrial Applications of Organofluorine Compounds," Ellis Horwood. Ltd. London, 1982. T. Satokawa, "Kinousei Fusso Kobunshi,"Nikkankogyo Shinbunsha, Tokyo, 1982.

2. C. Wu, W. Buck, and B. Chu, Macromolecules, 20, 93, 98 (1987); B. Chu, C. Wu, and J. Zuo, Macromolecules, 20, 700 (1987); B, Chu, C. Wu, and J. Zuo, Macromolecules, 22, 831 (1989).

3. W. H. Pirkle, D. W. House, and J. M. Finn, J. Chromatogr., 192, 143 (1980); A. Negishi, "Fusso no Kagaku," Maruzen, Tokyo, 1988.

4. J. Kip, P. van Haperen, and J. C. Kraak, J. Chromatogr., 356, 423 (1986).

5. C. Hirayama, H. Ihara, S. Nagaoka, and K. Hamada, J. Chromatogr., 465, 8 (1989).
6. R. C. B. Cubbon, Polymer, 6, 419 (1966).

7. T. Hagiwara, T. Shimizu, T. Ueda, H. Hamana, and T. Narita, J. Polym. Sci., Polym. Chem. Ed., 28, 185 (1990).

8. A. Matsumoto, T. Kubota, and T. Otsu, Macromolecules, 23, 4508 (1986).

9. T. Otsu, A. Matsumoto, and A. Tatsumi, Polym. Bull. (Berlin), 24, 459 (1990).

10. S. Iwatsuki, M. Kubo, M. Wakita, Y. Matsui, and H. Kanoh, Macromolecules, 24, 5009 (1991).

11. T. Oishi, M. Iwahara, and M. Fujimoto, Polym. J., 23, 1409 (1991).

12. J. M. Barrales-Rienda, J. G. Ramos, and M. S. Chaves, J. Polym. Sci., Polym. Chem. Ed., 17, 81 (1979).

13. T. Hagiwara, M. Kawashima, S. Koga, H. Hamana, and T. Narita, Polym. Prepr., Jpn., 40, 231 (1991).

14. A. Matsumoto, T. Kubota, and T. Otsu, Macromolecules, 23, 4508 (1990).

15. K. G. Olson and G. Butler, Macromolecules, 17, 2486 (1984).

16. For example: M. Yamamoto, Jpn Kokai Tokkyo Koho, JP 04,161,429 (1992); M. Shiraishi and S. Hayashi, Jpn Kokai Tokkyo Koho, JP 04,114,035 (1992); Y. Miyadera, Jpn Kokai Tokkyo Koho, JP 04,243,854 (1991).

17. T. Oishi, K. Kagawa, and M. Fujimoto, Macromolecules, 26, 24 (1993).

18. T. Otsu and M. Kinoshita, "Kobunshi Gousei no Jikkennhou," Kagaku Dojin, Kyoto, 1972, pp 69-91.

19. J. A. Riddick, W. B. Bunger, and T. K. Sakano, "Organic Solvents," 4th ed., John Wiley \& Sons, Inc., New York, N.Y., 1986.

20. A. Matsumoto, Y. Oki, and T. Otsu, Polym. J., 23, 201 (1991).

21. T. Oishi, H. Morikawa, and M. Fujimoto, Polym. J., 25, 41 (1993).

22. F. Tüdös, T. Kelen, T. Foldes-Berezsnich, and B. Turcsanyi, J. Macromol. Sci.-Chem., A10, 1513 (1976).

23. T. Alfrey, Jr. and C. C. Price, J. Polym. Sci., 2, 101 (1947).

24. T. Oishi, K. Matsusaki, and M. Fujimoto, Polym. J., 24, 1281 (1992).

25. T. Oishi, M. Iwahara, and M. Fujimoto, Polym. J., 23, 1409 (1991).

26. R. Z. Greenley, in "Polymer Handbook," J. Brandrup and E. H. Immergut, Ed., WileyInterscience Pubishershers, New York, N.Y., 1989.

27. T. Oishi, Kobunshi Kakou, 41, 314 (1992). 